\title{
Out-patient care for people with learning disability and epilepsy: evaluating the audit process
}

\author{
Helen Chubb, Michael Kerr and Joseph Joyce
}

\begin{abstract}
The notes of 24 individucts attending a clinic for people with learning discbility and epliepoy were roviowed for cill vitits in the year prececting and following the implementation of medical oudit standards for outpatient review. There was no deterioration in any standard. A sionilicant improvement was seen in recording of selaure trequency by selzure type, lockinty of sionatures, regular letters to generat practitioners and tho recording of selzure type and frequency in these. Modicat oudit con improve standards in epliepoy care, though lis influence on outcome is not known.
\end{abstract}

Psychiatrists in the field of learning disability will frequently be involved directly in the management of epilepsy in their patients due to the high prevalence of epilepsy in people with a learning disability (Beange \& Bauman. 1990), associated problems with medication (Flschbacher, 1985) and behaviour difficulties (Espie et al, 1989). The South Wales Audit Group in the psychiatry of learning disability recognised the importance of medical audit in this area, since standards for audit published to that date (Carpenter \& Kanagaratnam, 1993: Amaladoss \& Arumainayagam, 1994) were specifically related to in-patient populations.

The aim of this paper is twofold: first to describe the standard setting process and second to describe a study evaluating the impact of standard setting in the out-patient care of people with a learning disability.

\section{Standard setting}

Standard setting was a three stage process. At stage one, standards were agreed, by consent, in the South Wales medical audit group. The group consists of academic and NHS psychiatrists from the counties of Gwent, South Glamorgan, Mid Glamorgan, West Glamorgan and Dyfed. This process is one of discussion of research data and individual practice.
Essential to acceptance is the measurability and practicability of a standard so it can be returned to for evaluation of the audit. At stage two, a similar standard setting process was performed at a meeting of the neuroscience group (eplleptology, neurology, neurophysiology, neurosurgery and learning disability) of the University of Wales College of Medicine. Stage three involved a further meeting of the South Wales audit group.

The agreed standards to be met on each clinic or other appointment as well as the preand post-audit scores are set out in Table 1. These were agreed in February 1993.

\section{The study}

A method was chosen to perform a classical audit cycle involving the recognition of areas of concern, setting of standards, measuring of a baseline, and evaluation of effect of standard setting on this baseline. The evaluation was undertaken on patients attending the Developmental Epilepsy Clinic (established in 1991) run by the learning disability services at the University Hospital of Wales, Cardiff. In August 1994 case notes were assessed in 24 patients who had attended the clinic both in the year prior to the standard setting ( 1 March 1992-28 April 1993) and in the year which commenced one month after standard setting (1 April 1993-31 March 1994). Data was collected for both demographic details and the audit standards.

\section{Findings}

Statistical analysis was performed using SPSS.PC+. Non parametric statistics were used as the data was not normally distributed. The population ( $n=24$ ) had a mean age of 31.5 years (range 6-66), with 58\% females. The 
Table 1. Standards for out-patient visits of people with epilepsy and learning disability

\begin{tabular}{|c|c|c|}
\hline \multirow[b]{2}{*}{ Agreed standard } & \multicolumn{2}{|c|}{$\begin{array}{l}\text { Percentage of limes standard recched } \\
\text { (Number of times reached/Total out patient vistis } \times 100 \text { ) }\end{array}$} \\
\hline & Year prior to cuclit & Year following oudit \\
\hline $\begin{array}{l}\text { A witten record at each attendance of: } \\
\text { Current medication } \\
\text { Monthly selzure rate by selzure type } \\
\text { Side effects } \\
\text { Drug levels with dosage - recorded if taken } \\
\text { Some qually of life comment }\end{array}$ & $\begin{array}{l}66.7 \\
57.4 \\
22.3 \\
57.3 \\
52.8\end{array}$ & $\begin{array}{l}69.7 \\
85.2 \\
33.3 \\
60.0 \\
58.3\end{array}$ \\
\hline $\begin{array}{l}\text { Note keeping } \\
\text { Patient's name on top of page } \\
\text { Legible witting } \\
\text { Dated with year } \\
\text { Legible signature (at least once on each page) }\end{array}$ & $\begin{array}{l}96.3 \\
82.7 \\
98.9 \\
60.1\end{array}$ & $\begin{array}{c}97.8 \\
85.2 \\
100 \\
88.7^{\circ}\end{array}$ \\
\hline $\begin{array}{l}\text { Contained in letter to general practtioner } \\
\text { Letter or co-operation card on each attendance } \\
\text { Selzure type and frequency } \\
\text { Medication dose } \\
\text { Follow up time }\end{array}$ & $\begin{array}{l}84.8 \\
65.3 \\
79.6 \\
91.0\end{array}$ & $\begin{array}{l}98.9^{\circ} \\
89.2^{\circ} \\
87.4 \\
93.5\end{array}$ \\
\hline
\end{tabular}

"difference significant $P<0.05$

mean seizure frequency was 15.1 per month (range 0-90) before audit and 12.7 (range 090) after the audit. This was a non-significant change.

Patients were seen on average four times in each year period. Standards were scored as the percentage of times the criteria were reached in the total number of visits (number of times standard met/number of times seen $x$ 100). Table 1 shows the scores for each standard in the two time periods. Significant improvements were seen in recording of monthly seizure rate by seizure type (MannWhitney $U=147.5, P=0.0033)$; legibility of signature (Mann-Whitney $U=148.0, P=0.0031$ ); regular letter to general practitioner (MannWhitney $U=171.0, P=0.0026)$; writing seizure frequency in letter to GP (Mann-Whitney $U=$ 156.5, $P=0.0052)$.

\section{Comment}

We have clearly shown that the setting of audit standards in this clinic led to an improvement in several of the areas of out-patient management: the written record of seizure rate by type, legibility of doctors signatures and two aspects of communication with primary care-letter or cooperation card on each attendance and recording seizure type and frequency in the letter. The study has some limitations, in particular the use of retrospective note based data, the small number of patients and the lack of a control. However, it is reasonable to assume that these statistically significant improvements occurred due to the audit process.

Our audit standards appear to differ from previously published standards which have concentrated on aspects of therapy such as haematological monitoring (Carpenter \& Kanagaratnam, 1993) or outcome such as polypharmacy (Amaladoss \& Arumainayagam, 1994). This may well reflect our standard setting procedure which involved professionals outside of the field of learning disability. The standards were set to reflect quality of clinic attendance from which improved outcome might be obtained. Audit is a continuous process and standards are under review; some of the standards showed no significant improvement presumably because the pre-audit standard was high. Others, in particular the recording of side effects and comments on quality of life were poor both before and after audit. Clearly more direct intervention than purely standard setting is needed to improve these areas and this is being addressed. Locally we will do this through the audit sub-group by reassessing standards across South Wales, and feedback of these results on a regular basis. If this is unsuccessful, 
AUDIT

individual feedback would be an alternattve. Strategles such as structured inserts of the audit standards into the medical notes may be employed at a later date.

\title{
Conclusion
}

Epilepsy audit remains a high priority in the psychiatry of learning disability. Standards set with other professionals have the advantage of a consistent view to management irrespective of disability. Closing the audit cycle identified areas where further effort is needed to improve standards of care in particular assessing quality of life issues and recording side effects of medication. Further work is necessary to assess the impact of audit on patient outcome.

\section{References}

Amalndoss, A. S. P. \& ARUMannyagaM, M. (1994) Epllepsy in the mentally handicapped: a hospital survey. Psychiatric Bulletin, 18, 680-682.

Benuge, H. \& BAUMAN, A. (1990) Health care for the developmentally disabled: is it necessary? In Key Issues in Mental Retardation (ed. W. Fraser). pp 154-162. London: Routledige.

Carpeanter, P. K. \& Kannanratnum, S. (1993) Poychiatry of learning disabilities. Psychiatric Bulletin, 17, 91-92.

Espe, C. A. PAshiey, A. S., BONHMM, K. G., et al (1989) The mentally handicapped person with epilepsy: a comparative study investigating peychosocial functioning. Joumal of Mental Deficiency Reseanch, ss, 123-135.

FSCHRACHER, E. (1985) Mental handicap and epllepoy: are we still over treating? In Epllepsy and Mental Handicap (ed. C. Wood). RSM Round Table Series, No. 2. London: RSM Services.

- Helen Chubb, Psychiatric Registrar, Ely Hospital, Cowbridge Road East, Cardiff CF5 5XE; Michael Kerr, Lecturer, Welsh Centre for Learning Disabilities, Meridian Court, North Rd. Cardiff; and Joseph Joyce, Senior Registrar, Ely Hospital, Cowbridge Road East, Cardiff

*Correspondence

\section{Mental Health Care in China 中 國的 精 神 保 健 制 度}

\author{
State Policies, Professional Services and Family Reponsibilities \\ by Veronica Pearson
}

This book traces the development of psychiatric services in the People's Republic of China. Historical, policy and legal frameworks are constructed to provide a context in which psychiatric services may be better understood. The experience of both staff and patients in one particular hospital is examined in detail. The book raises questions about the similarities in the experience of psychiatric illness across significantly different cultures.

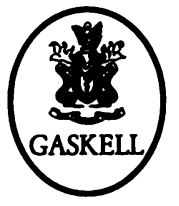

$\bullet £ 12.50 \bullet 218 p p . \bullet 1995 \bullet$ ISBN 0902241745

Available from bookshops and from the Publications

Department, Royal College of Psychiatrists, 17 Belgrave Square,

London SW1X 8PG (Tel. 0171-235 2351, extension 146) 